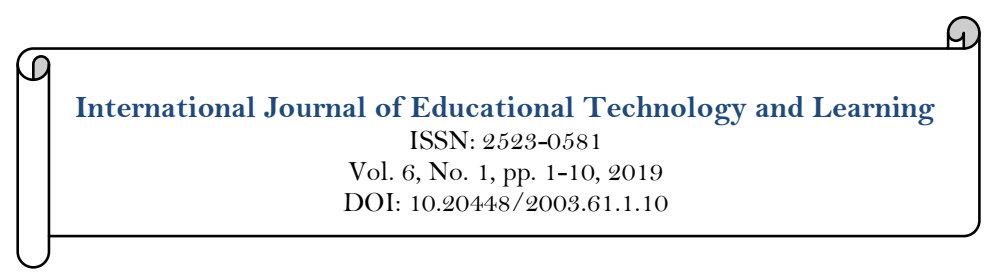

\title{
Typologies and Multidimensional Nature of Computer Use for Classroom Instruction in
} Secondary Education

\author{
Mwei, K. P. ${ }^{1 *}$ \\ Too, J. K. ${ }^{2}$ \\ Okioma, M. L. ${ }^{3}$ \\ ${ }^{1,2,3}$ Department of Curriculum, Instruction and Education Media, Moi University, Kenya \\ ${ }^{2}$ Email:mweikip@yahoo.com
}

\begin{tabular}{|c|c|}
\hline Abstract & \\
\hline $\begin{array}{l}\text { Computer technology has proved essential in all sectors of human endeavours } \\
\text { such as in industry and business. As a consequence, education has been the } \\
\text { main beneficiary of the emergence of the microcomputer being used in } \\
\text { financial management, administration and progressively in the classroom } \\
\text { for instruction. The experimental phase on the benefits of computer } \\
\text { technology for instruction is maturing. This paper explores through } \\
\text { reviewing literature the various ways computers have been used in the } \\
\text { classroom for instruction and through a pilot study, determine the } \\
\text { dimensions of computer use with the help offactor analysis. In the pilot study, } \\
\text { a sample of } 71 \text { respondents provided usable data. This paper helps us to } \\
\text { understand: (a) what is meant by "technology/computer use" in the context } \\
\text { of classroom instruction, the view that underpins a user's actual use of } \\
\text { technology; (b) the "evident" or "actual usage" of technology in the classroom } \\
\text { for instruction; and (c) the possible dimensions of this use. It is deemed } \\
\text { important to bring a common understanding of computer use with respect to } \\
\text { information and communication technology integration in pedagogy. }\end{array}$ & $\begin{array}{l}\text { Licensed: } \\
\text { This work is licensed under a } \\
\text { Creative Commons Attribution } 4.0 \\
\text { License. } \\
\text { Publisher: } \\
\text { Scientific Publishing Institute } \\
\text { Accepted: } 2 \text { May } 2019 \\
\text { Published: } 17 \text { May } 2019\end{array}$ \\
\hline
\end{tabular}

Funding: This study received no specific financial support.

Competing Interests: The authors declare that they have no competing interests.

\section{Introduction}

The teaching-learning process is as old as mankind and has been conducted both informally and formally (i.e., within a school set-up). To attain the desired outcomes, varied instructional technologies, media and instructional strategies have been used; for instance role-playing, demonstrations, apprenticeship and experimentation. All these efforts target the transmission of traditions/culture, skills, knowledge and attitudes to the younger generations throughout the ages in a given society. As a result, instructional strategies and technologies have been devised, adopted or adapted and used to enhance the process of instruction. However, the ultimate solution to the intrigues of facilitating effective and efficient instruction remains challenging and not yet surmounted.

Since the emergence of the microcomputer in the late 1970s (Roblyer \& Doering, 2010). it has led to efforts that aim to make extensive use of computer technology to enhance instructional process throughout the education systems of the world. Despite mixed results on the effectiveness of computers in education with respect to student achievement (also attitude, motivation, self-efficacy, etc.), varying degree of teacher computer usage and the rapid technological advancements in the twenty-first century; education stakeholders globally have taken (or taking) steps to infuse computers into schools and school systems. Recognizing that computers occupy an important position in education is implicit (or almost universally accepted), even among 
governments and individuals that are apprehensive about the ideological and methodological facets of computers in education (Ministry of Education, 2005; Ministry of Information and Communications, 2006).

Furthermore, Voogts, Knezek, Cox, Knezek, and Brummellhuis (2011) and Jegede (2008) concur that it is apparent information and communication technologies (ICTs) have a primary place in the skills and learning of the $21^{\text {st }}$ century. ICTs have subsequently become essential tools in the contemporary information society and knowledge economy, impacting remarkably on the lives of citizens (and particularly the youth) the world over (McLoughlin \& Lee, 2007; Pelgrum \& Voogt, 2000; Voogt, 2010). This profound impact is most considerable in education because computers in particular are becoming increasingly available to schools and especially in developing countries. This availability is a result of the concerted efforts between government and nongovernmental organizations and other private/individual entities.

The study is premised around the belief that computer technology plays a pivotal role in the instructional process. Therefore the need to clarify on the typologies of computer use in pedagogy: the definition of computer use and classifications.

We present this paper under the following:

a) We survey the various ways "computer/technology" has been used.

b) We suggest views on the nature of computer/technology use based on "technology affordances."

c) We propose a classification of computer/technology use as a consequence of this view and technology affordances into: traditional and constructivist use and their relationship thereof.

d) We deduce four main uses of computer/technology for curriculum instruction.

e) We present the results of a pilot study to determine the optimal multidimensional nature of a computer use scale that was developed.

\section{Literature Review}

\subsection{Definition of Computer/Technology Use}

This section highlights the various ways of computer use and the ensuing definitions. To begin with, "computer" has encompassed a variety of ways to distinguish it in the context of user disposition. For example, the computer has been seen as (a) a technology, that is, computer falling into the wider category as another form of technology, (b) an innovation or (c) an agent of change (Culp, Honey, \& Mandinach, 2003; Gulbahar \& Guven, 2008; Papanastasiou \& Angeli, 2008). According to Culp et al. (2003) as a change agent, computer catalyses various other changes in the content, methods, and general quality of the instructional process, in this manner ensuring constructivist inquiry-based classrooms. With these various approaches, different authors discern computers in education differently, yet their views have a common denominator; that of computer use. Computers in education have chiefly been used for school administration, management and gradually for instruction.

As a result, several terms have been utilized in relation to computers in education:

i). Acceptance which refers to "user's willingness to adopt and use technology for the tasks it is designed to support" (Teo, 2010).

ii). Diffusion which is the process by which an innovation is adopted and gains acceptance by members of a certain community (Birch \& Burnett, 2009; Venkatesh, Morris, Davis, \& Davis, 2003).

iii). Implementation defined as "any use of IT [information technology] in the teaching of students; the use of computer technology for instructional purposes" (Wanjala, 2010). Integration which refers to "making pedagogical and curriculum changes to include technology" (Angers \& Matchmes, 2005). A "shortrange" definition of technology integration is given by Kurgat (2011) as "the effective use of technology by teachers and students in the classroom" (p. 23). According to Lloyd (2005) "to integrate is to seamlessly combine components, parts or elements into a complex but harmonious whole" (p.5). This term "integration" is receiving a lot of attention with respect to ICTs in education.

iv). Usage has been defined as "an indicator of adoption, acceptance as well as diffusion" (Usluel, Askar, \& Bas, 2008).

Nevertheless, defining the concept of computer use in pedagogy or classroom instruction is very complex because teachers use computers in the teaching-learning process in diverse ways, depicting heterogeneous field of computer application (Hogarty, Lang, \& Kromrey, 2003; O’Dwyer, Russell, \& Bebell, 2004). Different authorities have advanced different approaches to classify computers in education. A critical look at the literature revealed two convergent modes of classification: traditional and constructivist. The former classification is largely dependent on the static view of "technology affordances" (Boyle \& Cook, 2004; Conole \& Dyke, 2004a; Tanner \& Jones, 2000) while the latter is largely dependent on the dynamic view of technology affordances that cut-across teacher innovative usage of ICT (Cuban, Kirkpatrick, \& Peck, 2001; Windschitl \& Sahl, 2002).

\subsection{Views on the Nature of Computer/Technology Use}

The basic view presented here is that any technology can be used as was originally intended or creatively used beyond its original design intentions. It is without doubt therefore, that technology use is dependent on a user's "view on technology affordances." Thus, we defined technology affordances and its implications to the overall 
usage of technology. Technology affordances can be limited to the intended, prescribed or designed function of the technology (Conole \& Dyke, 2004a). In general, an affordance refers to "a situation where there exists a relationship between an organism (such as teacher, student) and an object of interest (such as computer), where the object is perceived in relation to the needs of the organism" (Hammond, 2010). (Note the term "affordance" has its origin in ecology; refer (Conoles \& Dyke, 2004b). Affordances of technology in relation to the classroom setting, according to Boyle and Cook (2004) provide a "theoretical basis for the use of ICT to support learning." Tanner and Jones (2000) assert that affordances describe the potential for action, the capacity of an environment or an object to facilitate the intentions of the organism within a particular problem situation. Technology, as designed, provides users an opportunity to "use" it in a manner dependent on the creativity and innovativeness of the user or lack of it thereof. At the minimum, a user with the necessary skills and competence can use technology as per its design purpose.

There is a conversation about what exactly is technology affordance, in this paper; the two extremes are denoted as "static view" and "dynamic view":

i). Static view of technology affordances is considered as the view of technology in facilitating and enabling usage as per the intended, prescribed, or designed purpose or function of the technology.

ii). Dynamic view of technology affordances is perceived as the view of technology in facilitating and enabling the use of the technology both as intended and unintended in the design of technology. The unintended usage implies that the technology serves the user according to how it is innovatively and creatively put into use beyond its designed purpose. Although the design of technology may be an inherently limiting factor, the technology provides services over and above the intention of the designer/developer.

We take a broad view of the definition of technology affordance in relation to the concept of "computers in education." In this broad view, resident in the overall dynamic view, we submit that technology affordances in respect to teacher computer use in the classroom are the opportunities presented to the teacher by the computer in support of pedagogical or instructional tasks and the social support for professional development including a community of practice and mentorship.

In spite of the imprecise definitions of computer use, research studies have reported a variety of pedagogical usage of computer (and its peripheral technologies) and varying degree of these usage among teachers in different subject specializations or departments, among teachers within a school, among teachers across schools and across educational levels (Cuban et al., 2001; Garcia-Valcarcel, 2010; Sang, Valcke, Van Braak, \& Tondeur, 2009; Teop, 2009a; Windschitl \& Sahl, 2002). It is worthwhile to note that irrespective of the definition of technology affordance and hence the view on the nature of technology use, there is overwhelming evidence indicating robust computer usage in education.

\subsection{Classification of Pedagogical Usage of Computers in Education}

The mode of classification we presented in this subsection is based on either a traditional or a constructivist argument, a consequence of the view on the nature of technology use. In the main, these classifications are anchored on the design and/or the innovative/creative use of the computer with reference to both the designer and the user of the technology. Pedagogical usage is based on two main attributes:

i). The extent that the technology is designed to engage the learner cognitively, which is also considered in this paper as the quality of engagement.

ii). The number of interactions (social and psychomotor): two-way (technology-teacher, technologylearner) or three-way (a threesome interaction among: learner-technology-learner or learnertechnology-teacher). It is also possible that technology can support teaching-learning beyond the classroom to include the public. The two terms (quality of engagement and quantity of interactions) are explained next.

Quality refers to the degree of learner cognitive engagement with the technology, teacher and/or peers mediated by technology. For example, when a computer poses a question in "drill and practice" instructional programs and the learner chooses among given options, the quality of engagement is low because the technology supports low order thinking skills (LOTS) while in a problem-solving scenario the quality is high because the technology calls for high order thinking skills (HOTS). Although the boundary between LOTS and HOTS is contestable, the logic behind these arguments is based on Bloom's Taxonomy of the cognitive domain (that is, LOTS are engagements on knowledge, comprehension and application while HOTS are engagements on analysis, synthesis and evaluation).

The quantity of (psychomotor or social) interactions refers to the number of stimulus-response dyads or pairs in a conversational setting that makes a complete communication cycle. For an illustration, when a computer poses a question (stimulus), a learner chooses among given options (first or primary response), and finally the computer evaluates the learner (second or secondary response). In this scenario, the quantity of interaction is of order three (stimulus - primary response - secondary response). However, in a HOTS scenario (such as problem-solving), the order of the number of interactions becomes higher. 


\subsection{Traditional Classification}

The traditional classification is determined merely by the design and the development of the technology courseware or instructional software (that is, the static view of affordances of technology systems). One of the earliest classifications in this category of computer use was either as a tutor or a tutee (Hawkridge, Jaworski, \& McMahon, 1990). Being a tutor, the technology will "teach" the learner in the same way a teacher does. Twoway interactions between the technology and the learner are emphasized, thus the quality demanded is low and the quantity is low order.

When the learner "teaches" the computer (as a tutee, for example, in a LOGO environment) both the quality and quantity becomes higher. Following in this tradition, other classifications emerged as advancement in technology continued. For example, Alessi and Trollip (1985) and Handal and Herrington (2003) gave a five-level classification of pedagogical use as drill and practice, tutorial, tests, games and simulation.

Hogarty et al. (2003) classified pedagogical use based on "who - the actor or the technology user" and "what - the purpose of the technology" into the following classes: (a) Teacher software use into two factors (i) Instructional software use (tutorial, simulations, drill and practice, games), and (ii) application software use (word processors, spreadsheets, databases, web browsers, presentation software). (b) Student software use into two factors (Similar to (a) Teacher software use, above). (c) Integration of computers in the classrooms: Both individual and group instruction and the promotion of both independent and student-centered learning (e.g. "as a research tool for student" and "as a classroom presentation tool"). (d) Personal use - teachers' personal use of the computer (e.g. "as a research tool" and "as a communication tool").

Similar to the work of Hogarty et al. (2003), Hung and Hsu (2007), classified computer use in the classroom into (a) basic instructional tool for example playing video, content demonstration, and instructional software for students; and (b) advanced instructional use for students' cooperative and individual learning (similar to Hogarty et al. (2003), classification "Integration of computers in the classrooms"). However, Cuckle and Clarke (2002) based their categorization on the actual activities a computer can be put into use: (a) preparing teaching materials such as word processing, CD ROMs, spreadsheets; and (b) teaching in the classroom. Papanastasiou and Angeli (2008) based on this static view of computer applications, classified computer use into (a) common applications such as Word, Email, Excel; and (b) specialized applications such as Stage Cast Creator, Front Page, and Publisher.

The above classification as judged according to the quality of engagement and quantity of interactions are shifting into a dichotomy: constructivist versus traditional (also behaviourist or transmissionist) use (Riel \& Becker, 2001; Teoo, Chai, Hung, \& Lee, 2008; Teos, 2009b). Traditional use of ICT attains the same traditional goals - as without ICT - with no considerable changes to the classroom activities (such as drill and practice).

The teacher remains dominant and principal user of ICT, teacher-centric instructional paradigm. Constructivist pedagogical use of ICT expands classroom boundaries, connect students to real-world events, and guide students to become independent learners (learner - centred). Teoo et al. (2008) classified pedagogical uses into: traditional such as tutorials, drill and practice, web searches for factual information and constructivist such as computer modeling and simulation programs, computer supported collaborative learning, and presentation software. The traditional mode of classification is "just" used to distinguish between different computer applications and the way they were designed and expected to be used.

\subsection{Constructivist Classification}

This classification is based on research findings and it represents the "actual or measured pedagogical usage" of ICT by both teachers and learners, that is, the teacher or learner reported educational use of the computer in the classroom. Teacher technology use, for example, is considered as a multidimensional and a composite behaviour (Russell, Bebell, O’Dwyer, \& O’Connor, 2003).

Traditional operationalization of technology use is subjected to empirical verification through statistical means. Exploratory and confirmatory analyses have mainly been used to make these empirical justifications. For example, O'Dwyer et al. (2004) conducted a survey among elementary classroom teachers and confirmed a four-factor pedagogical usage of ICT as under: (a) Teachers' use of technology for delivering instruction, (b) Teacher-directed student use of technology during class time, (c) Teacher-directed student use of technology to create products, and (d) Teachers' use of technology for class preparation. O'Dwyer et al identified three players: teachers, students and technology. While the role of the teacher tends towards traditional one (more teacher-centric as a result of 'directing' student activities), a constructivist role was however given to the learner (student-centred among other characteristics).

Hsu (2010) conducted an exploratory factor analysis on ICT scale which resulted into six factors (a) Information collection and preparation; (b) Material production and troubleshooting; (c) Communication and sharing; (d) Planning, Teaching and evaluation; (e) Professional development and self-study; and (f) Ethics, health and safety issues. The following items, for instance, operationalized factors a, b, and d:

i). Factor a (Preparation): Used a computer to create lecture notes, class material and exams questions.

ii). Factor $\mathbf{b}$ (Delivery): Used presentation software to present course material in class.

iii). Factor d (Evaluation): Analyzed students' learning progress... and provided worksheet for students.... 
This mode of classification does not necessarily identify the particular computer application/courseware or program used but only in the way these applications/programs are used in the classroom. For example, during "preparation" Hsu (2010) a teacher can use a number of computer applications such as MS Word, MS PowerPoint; but these applications are not necessarily identified during statistical analysis such as in factor analysis. In the constructivist classification, both views on technology affordances are plausible - the main concern here is "the actual use" and how the resultant factors are labeled by the researcher. This labeling however is subjective.

\subsection{Linking Traditional and Constructivist Computer Use}

The traditional classification of pedagogical use of ICT is highly dependent on the static view of technology affordance as prescribed by the designer, although innovative/creative use of technology beyond the designer's anticipation is possible. Therefore, this tendency to innovatively use technology leans toward a dynamic view of technology affordance, even with simple technology (or with traditionally intended use of technology, refer to Cuban et al. (2001) can signify a constructivist use of ICT.

This innovative use of ICT is only justifiable empirically. For that reason, a convergence between traditional and constructivist classifications of pedagogical use of ICT is proposed to be highly probable. When clear characteristics (measures or observable uses) of computer use that are traditionally identified are outlined (or operationalized) and subjected to exploratory and/or confirmatory tests, a coherent understanding of pedagogical use of the computer (a latent construct/variable) would emerge.

As a consequence, (a) in both traditional and constructivist classifications the quality of cognitive engagement and quantity of social and psychomotor interactions are a function of the technology itself, its capabilities and affordances and (b) pedagogical use is dependent on how the teacher or learner engage or interact with the technology. Through careful examination of computer use variable, this paper identifies "instructional use of computer" consisting of mainly four interwoven activities:

i). Planning for instruction: preparation of lesson plans, lesson notes, worksheets, and scheming.

ii). Instructional delivery: actual lesson presentation, demonstration, simulations. This activity brings the teacher and the learner into communication environment - with engagements and interactions.

iii). Evaluation: tests, assignments, projects. In this activity, computer enables the teacher to prepare for learner evaluation; administration can be given either with or without the use of computer.

iv). Reporting: test analysis and report compilation. This is mainly a teachers activity (although there are possibilities of teacher-learner collaboration) mediated by technology.

Considering instructional use of computer in this way has mainly two advantages: (a) it provides a way of measuring pedagogical/instructional usage with several question items (indicators or manifest variables) that are very specific and (b) it suggests a computer use scale that can be subjected to both exploratory and confirmatory analyses in order to establish "latent structure" or the multidimensional nature of the computer for pedagogical/classroom use.

\section{Design and Methodology}

\subsection{Research Instrument}

The literature reviewed provided the basis for the development of a computer use scale based on the four identified instructional uses, namely: planning for instruction, instructional delivery, evaluation and reporting. In this study, Computer Use scale consisted of 15 Five-point Likert-type items (labeled CU01 - CU15), ranging from $0=$ never, $1=$ rarely, $2=$ sometimes, $3=$ Very often, and $4=$ Always was developed based on the literature reviewed. Basically, the Tondeur, Van Braak, and Valcke (2007) computer use scale with three dimensions: computer as an "Information Tool", computer as a "Learning Tool" and "Basic computer Skills" was modified by adding one dimension on "Computer Use for Teacher Support” with 5 items.

\subsection{Sampling Procedures}

This survey (a pilot study) was conducted in five secondary schools in Uasin Gishu County, Kenya that had computers (under the Government's Economic Stimulus Program) set for classroom instruction. Filled questionnaires from 71 pilot cases were received and were all usable.

\section{Results and Discussions}

\subsection{Scale reliability}

Reliability for the computer used scale meant its internal consistency. This is because the responses from a single administration of the questionnaire were analyzed. According to Fraenkel and Wallen (2000), reliability refers to "the consistency of the scores obtained - how consistent they are for each individual from one administration of an instrument to another and from one set of items to another" (p. 176). Computer Use scale resulted in a reliability of Alpha coefficient $\alpha=.69$ [.70]. This reliability was deemed good enough $(\alpha \geq .70$, (Santos, 1999) for further scale analysis. 


\subsection{Item correlations}

As a prerequisite for Factor Analysis, item correlations of the scale were computed. All correlations were significant at $\mathrm{p}<.01$. Note, however, correlations are affected by sample size such that the larger the size of the sample, small correlation coefficients (in absolute terms) may become significant. Therefore, reporting and interpreting the size of correlations were necessary.

According to Taylor (1990) proposal on a review of reported correlations in empirical studies, though arbitrary, presented the following ranges to interpret the strength of correlation coefficients: $\leq 0.35$ as low or weak correlations, between 0.36 and 0.67 as modest or moderate correlations, between 0.68 and 0.90 as strong or high correlations, and $>0.90$ as very high correlations. Majority of these correlations were either modest or moderate.

\subsection{Factor Analysis of the Computer Use Scale}

To identify the multidimensional nature (Roy, Tarafdar, Ragu-Nathan, \& Marsillac, 2012) of computer use scale as modified (Scale B) from Tondeur et al. (2007) (Scale A), the scale was factor-analyzed using Principal Component Analysis (PCA), a data reduction technique (Fabrigar, MacCallum, Wegener, \& Strahan, 1999; Solanas, Manolov, Leiva, \& Richards, 2011). Table 1 shows the results of PCA using SPSS 20.0 software, with Promax (an oblique type) rotation. PCA adequacy was met (KMO $=0.74$; Bartlett's $\chi^{{ }^{2}(105)}=$ $1207.00 ; p<.001$; and determinant $\left.=6.77 \times 10^{-9}\right)$. PCA was able to extract four components from the computer use scale (Component 1: items CU 01, 02, 03, 05, 06 and 12; Component 2: items CU04, 07, 08 and 09; Component 3: items CU13, 14 and 15 and Component 4: items CU10 and 11). The four extracted components explained a total of $82.93 \%$, that is, $35.64 \%, 21.35 \%, 17.13 \%$ and $8.80 \%$ respectively using Kaiser Criterion of eigenvalue greater than 1.0; no cross-loaders (that is, loadings $>0.32$ for an item in at least two components) were found.

Table-1. Principal Component Analysis of Computer Use scale.

\begin{tabular}{|c|c|c|c|c|c|c|c|}
\hline \multicolumn{8}{|c|}{ Total Variance Explained } \\
\hline \multirow[t]{2}{*}{ Component } & \multicolumn{3}{|c|}{ Initial Eigenvalues } & \multicolumn{3}{|c|}{$\begin{array}{c}\text { Extraction Sums of Squared } \\
\text { Loadings }\end{array}$} & \multirow{2}{*}{$\begin{array}{c}\text { Rotation Sums of } \\
\text { Squared Loadings } \\
\text { Total }\end{array}$} \\
\hline & Total & $\begin{array}{c}\text { \% of } \\
\text { Variance }\end{array}$ & $\begin{array}{c}\text { Cumulative } \\
\%\end{array}$ & Total & $\begin{array}{c}\text { \% of } \\
\text { Variance }\end{array}$ & $\begin{array}{c}\text { Cumulative } \\
\%\end{array}$ & \\
\hline 1 & 5.346 & 35.642 & 35.642 & 5.346 & 35.642 & 35.642 & 5.188 \\
\hline 2 & 3.204 & 21.358 & 57.000 & 3.204 & 21.358 & 57.000 & 3.333 \\
\hline 3 & 2.569 & 17.128 & 74.128 & 2.569 & 17.128 & 74.128 & 2.675 \\
\hline 4 & 1.321 & 8.804 & 82.932 & 1.321 & 8.804 & 82.932 & 2.258 \\
\hline 5 & .655 & 4.366 & 87.298 & & & & \\
\hline 6 & .562 & 3.749 & 91.046 & & & & \\
\hline 7 & .414 & 2.757 & 93.803 & & & & \\
\hline 8 & .287 & 1.913 & 95.716 & & & & \\
\hline 9 & .210 & 1.400 & 97.116 & & & & \\
\hline 10 & .179 & 1.196 & 98.312 & & & & \\
\hline 11 & .108 & .722 & 99.034 & & & & \\
\hline 12 & .076 & .510 & 99.544 & & & & \\
\hline 13 & .039 & .257 & 99.801 & & & & \\
\hline 14 & .016 & .106 & 99.907 & & & & \\
\hline 15 & .014 & .093 & 100.000 & & & & \\
\hline
\end{tabular}

Notes: Extraction Method: Principal Component Analysis.

a. When components are correlated, sums of squared loadings cannot be added to obtain a total variance.

The resultant factor structure of the Computer Use scale Table 2 did not seem to support the proposed four-dimensional structure as modified from Tondeur et al. (2007). This is because the items in the Tondeur et al. (2007) scale did not load as expected on their respective dimensions (Information Tool, Learning Tool and Basic Computer Skills) and the added dimension (Computer use for Teacher Support). Therefore, a new optimal factor structure of computer use scale was sought.

To empirically determine the optimal number of components to be retained for this scale, Horn's parallel analysis (PA) was conducted (Fabrigar et al., 1999; Franlin, Gibson, Robertson, Pohlmann, \& Fralish, 1995; Stellefson \& Hanic, 2008; Watkins, 2005) using Monte Carlo PA approach (Watkins, 2010). The following inputs were fed to the software according to Dinno (2009): number of participants $=71$, number of items $=15$ and number of replications $=1000$. Figure 1 shows a scree plot of the results of PCA and PA on the same axes (extracted eigenvalues from PCA and random eigenvalues from PA). Based on the PA procedure, three components must be extracted. This criterion is indicated when the value of the random eigenvalue (from PA) is greater than the extracted eigenvalue (from PCA). 
With this finding, another PCA with the 15-items of computer use scale was performed, this time restricting the number of components to be extracted to three. The results of the PCA were inconsistent because the two indicators CU10 and CU11 loaded negatively on Component 1. Consequently, a decision was made to remove items CU10 and CU11 which had previously loaded on Component 4.

Table-2. Rotated Pattern Matrix for Computer Use Scale.

\begin{tabular}{|c|c|c|c|c|}
\hline \multirow[t]{2}{*}{ Item } & \multicolumn{4}{|c|}{ Component } \\
\hline & 1 & 2 & 3 & 4 \\
\hline $\mathrm{CUO} 2$ & $(.958)$ & -.028 & .053 & .000 \\
\hline CU12 & $(.956)$ & -.012 & .020 & -.051 \\
\hline CU06 & $(.925)$ & -.003 & -.001 & -.070 \\
\hline CU05 & $(.907)$ & .056 & -.091 & .046 \\
\hline CUO1 & $(.821)$ & -.002 & -.157 & .041 \\
\hline CU03 & $(.803)$ & -.031 & .196 & .004 \\
\hline CUO7 & .012 & $(.982)$ & -.016 & -.042 \\
\hline CU09 & -.053 & $(.957)$ & .003 & -.094 \\
\hline $\mathrm{CUO4}$ & -.078 & $(.847)$ & -.017 & -.040 \\
\hline CUo8 & .111 & $(.784)$ & .033 & .198 \\
\hline CU15 & -.027 & -.026 & $(.976)$ & .021 \\
\hline CU13 & -.129 & -.068 & $(.926)$ & -.045 \\
\hline $\mathrm{CU} 14$ & .168 & .103 & $(.858)$ & .013 \\
\hline CU11 & .043 & -.047 & -.126 & $(.900)$ \\
\hline CU10 & -.089 & .058 & .135 & $(.856)$ \\
\hline
\end{tabular}

Rotation Method: Promax with Kaiser Normalization. Rotation converged in 4 iterations.

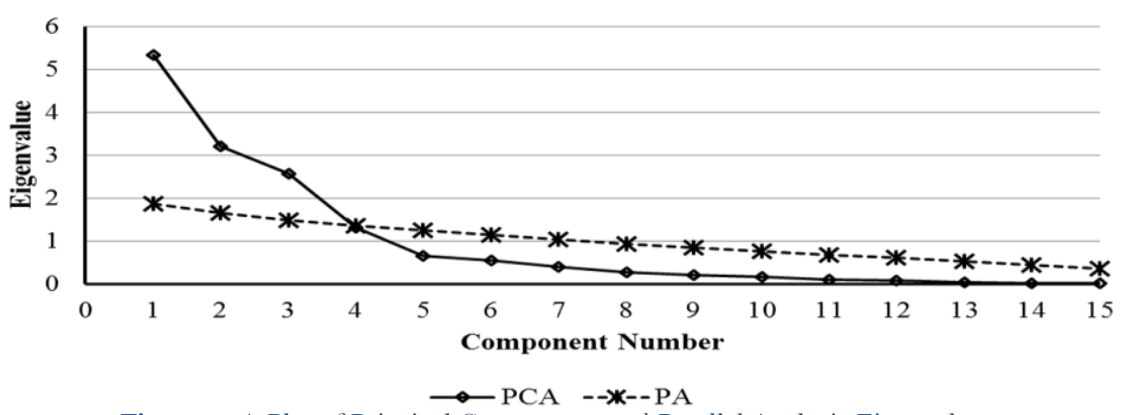

Figure-1. A Plot of Principal Components and Parallel Analysis Eigenvalues. Note: $\mathrm{PCA}=$ principal components analysis, $\mathrm{PA}=$ parallel analysis .

Table-3. Computer use scale comparisons.

\begin{tabular}{c|l|c|c|c}
\hline \multicolumn{1}{c}{ ITEM } & \multicolumn{2}{c}{ SCALE } \\
\hline No. & Statement & A & B & C \\
\hline CU01 & Students use the computer as an encyclopedia & IT & IT & SLCU \\
\hline CU02 & The students use the computer to select and retrieve information & IT & IT & SLCU \\
\hline CU03 & The students use the computer to store information & IT & IT & SLCU \\
\hline CU04 & I use the computer as a demonstration tool & IT & IT & TTCU \\
\hline CU05 & The students use the computer for writing text & IT & IT & SLCU \\
\hline CU06 & The students use the computer for further research on specific subject matter & LT & LT & SLCU \\
\hline CU07 & I use the computer to prepare scheme of work & n/a & TS & TTCU \\
\hline CU08 & I use the computer to make lesson notes & n/a & TS & TTCU \\
\hline CU09 & I use the computer to prepare worksheets & n/a & TS & TTCU \\
\hline CU10 & I use the computer to prepare for learner evaluation tests, projects, etc). & n/a & TS & X \\
\hline CU11 & I use the computer enter and analyze students' marks & n/a & TS & X \\
\hline CU12 & The students use the computer to catch up' if fallen behind with class work & LT & LT & SLCU \\
\hline CU13 & The students use the computer to practice knowledge or skills & LT & LT & SKCU \\
\hline CU14 & I teach students how to make good use of the keyboard and mouse & BCS & BCS & SKCU \\
\hline CU15 & I teach students to use computer terms correctly & BCS & BCS & SKCU \\
\hline Note: & & &
\end{tabular}

$\mathrm{A}=$ Tondeur et al. (2007) scale dimensions: IT = Information Tool, LT = Learning Tool and BCS = Basic Computer Skills

$\mathrm{B}=$ Modified Scale dimensions: TS $=$ Teacher Support (for pilot study).

$\mathrm{C}=$ Modified scale dimensions through PCA: SLCU $=$ Computer Use for Student Learning, TTCU $=$ Computer Use for Teaching and SKCU $=$

Computer Use for Basic Skills.

$\mathrm{n} / \mathrm{a}=$ not applicable

$\mathrm{X}=$ Dropped. 
A final PCA was conducted after removing items CU10 and CU11 from the analysis and a parsimonious interpretable model (Scale C) emerged Table 3.

The components were labeled: Component 1 - computer as a learning tool (SLCU, items CU 01, 02, 03, 05, 06 and 12with reliability of Cronbach alpha, $\alpha=0.94$ ), Component 2 - computer as a teaching tool (TTCU, items CU04, 07, 08 and 09 with reliability of Cronbach alpha, $\alpha=0.90$ ) and Component 3 - computer use for basic skills (SKCU, items CU13, 14 and 15 with reliability of Cronbach alpha, $\alpha=0.91$ ). The three components with eigenvalues 5.04, 3.18 and 2.55 contributed $38.78 \%, 24.45 \%$ and $19.60 \%$ respectively, explaining a total variance of $82.83 \%$ in computer use.

\section{Conclusion}

This paper presents conclusions based on the two main research objectives:

i. Having looked at definition and views on the nature of technology/computer use, and the implicit role of technology affordance; we conclude that:

a) Researchers need to explicitly clarify their approach in classifying "technology use" in order to encourage comparison of different works.

b) Technology affordance is not the only factor that predisposes a user of technology to a particular use. These other factors can be structural user characteristics such as age and gender; cultural user characteristics such as attitudes, social influence and self-efficacy; or institutional support.

ii. Computer use is a multifaceted (multidimensional or composite) construct. It is important, therefore, to be cognizant of the reality that, first, although optimal computer usage structure emerged, some dimensions were lost. In essence, it is imperative to note that computer use will, as per the emphasis placed on the possible dimensions, include but not limited to the above; classroom control, computers for information seeking, storage and retrieval. Secondly, the process of labeling the construct (computer use) dimensions is subjective, being dependent on the labeler.

\section{References}

Alessi, S. M., \& Trollip, S. R. (1985). Computer-based instruction: Methods and development. Englewood Cliffs, NJ: Prentice-Hall, Inc.

Angers, J., \& Matchmes, K. (2005). An ethnographic-case study of beliefs, content factors, and practices of teachers integrating technology. The Qualitative Report 10(4), $771-794$.

Birch, D., \& Burnett, B. (2009). Bringing academics on board: Emerging institution-wide diffusion of e-learning environments. Australasian Journal of Educational Technology, 25(1), 117-134.

Boyle, T., \& Cook, J. (2004). Understanding and using technological affordances: A commentary on Conole and Dyke. Research in Learning Technology, 12(3), 295-299.

Conole, G., \& Dyke, M. (2004a). Understanding and using technological affordances: A response to Boyle and Cook. Research in Learning Technology, 12(3), 301-308.

Conoles, G., \& Dyke, M. (2004b). What are the affordances of information and communication technologies? Research in Learning Technology, 12(2), 113-124.

Cuban, L., Kirkpatrick, H., \& Peck, C. (2001). High access and low use of technologies in High school classrooms: Explaining an apparent paradox. American Educational Research Journal, 38(4), 813-834.

Cuckle, P., \& Clarke, S. (2002). Mentoring student-teachers in schools views, practices and access to ICT. Journal of Computer Assisted Learning, 18, 330-340.

Culp, K. M., Honey, M., \& Mandinach, E. (2003). A retrospective in twenty years of educational technology policy. Retrieved from http://www.nationedtechplan.org/participate/20years.pdf.

Dinno, A. (2009). Exploring the sensitivity of Horn's parallel analysis to the distributional form of random data. Multivariate Behavioural Research, 44(3), 362-388.

Fabrigar, L. F., MacCallum, R. C., Wegener, D. T., \& Strahan, E. J. (1999). Evaluating the use of exploratory factor analysis in psychological research. Psychological Methods, 4(3), 272-299.

Fraenkel, J. R., \& Wallen, N. E. (2000). How to design and evaluate research in education (4th ed.). Boston: McGraw-Hill.

Franlin, S. B., Gibson, D. J., Robertson, P. A., Pohlmann, P. A., \& Fralish, J. S. (1995). Parallel analysis: A method for determining significant principal components. Journal of Vegetation Science, 6(1), 99-106.

Garcia-Valcarcel, A. (2010). Integrating ICT into teaching-learning process. British Journal of Educational Technology, $41(5)$, E75-E77.

Gulbahar, Y., \& Guven, I. (2008). A survey on ICT usage and the perceptions of social studies teachers in Turkey. Education, Technology \& Society, 11(3), 37-51.

Hammond, M. (2010). What is an affordance and can it help us understand the use of ICT in education? Retrieved from http://dx.doi.org/10.1007/s10639-009-9106-z.

Handal, B., \& Herrington, A. (2003). Mathematics teachers' beliefs and curriculum reform. Mathematics Education Research Journal, 15(1), 59-69.

Hawkridge, D., Jaworski, J., \& McMahon, H. (1990). Computer in third-world schools: Examples experience and issues. London: Macmillan. 
Hogarty, K., Lang, T. R., \& Kromrey, J. D. (2003). Another look at technology use in classrooms: The Development and validation of an instrument to measure teachers' perceptions. Educational and Psychological Measurement, 63(1), 139-162.

Hsu, S. (2010). Developing a scale for teacher integration of information and communication technology in Grades 1-9. Journal of Computer Assisted Learning, 26(3), 175-189.

Hung, Y.-W., \& Hsu, Y.-S. (2007). Examining teachers' CBT use in the classroom: A study in secondary schools in Taiwan. Educational Technology \& Society, 5(2), 183-206.

Jegede, P. O. (2008). ICT attitudinal characteristics and use level of Nigerian teachers. Issues in Information Science and Information Technology, 5, 261-266.

Kurgat, J. S. (2011). Towards the integrated e-learning approach in Kenyan secondary schools. The perception of Business Studies teachers and students in selected E-schools (Unpublished Doctoral Thesis). Moi University, Eldoret.

Lloyd, M. (2005). Towards a definition of the integration of ICT in the classroom. In AARE (Eds.).Proceedings AARE '0 5' Educational Research-Creative Dissent: Constructive Solutions, Parramatta, New South Wales. Retrieved from https://eprints.qut.edu.au/secure/00003553/01/llo05/20.pdf.

McLoughlin, C., \& Lee, M. J. W. (2007). Social software and participatory learning: Pedagogical choices with technology affordances in the Wed 2.0 era. In ICT: providing choices for learners and learning. Proceedings of ASCILITE, Singapore. Retrieved from http://www.ascilite.org.au/conferences/singapore07/procs/mcloughlin.pdf.

Ministry of Education, S. a. T. (2005). A policy framework for education, training and research. Sessional Paper No. 1 of 2005. Republic of Kenya.

Ministry of Information and Communications. (2006). National information and communication technology (ICT) policy. Retrieved from http://www.information.go.ke.

O’Dwyer, L. M., Russell, M., \& Bebell, D. J. (2004). Identifying teacher, school and district characteristics associated with elementary teachers' use of technology: A multilevel perspective. Education Policy Analysis Archives, 12(48), 1-33.

Papanastasiou, E. C., \& Angeli, C. (2008). Evaluating the use of ICT in education: psychometric properties of the survey of factors affecting teachers teaching with technology (SFA-T3). Educational Technology \& Society, 11(1), 69-86.

Pelgrum, W. J., \& Voogt, J. M. (2000). Information and communication technology (ICT) in lower secondary schools in Bulgaria, the Czesh Republic, Hungry, Lithuaning and the Russian Federation. Education Technology Research Development, 48(3), $111-121$.

Riel, M., \& Becker, H. (2001). Teacher professional engagement and constructivist-compatible computer use. Retrieved from http://www.crito.uci.edu/tlc/findings/report7.html.

Roblyer, M. D., \& Doering, A. H. (2010). Integrating educational technology in teaching (5th ed.). Boston: Allyn \& Bacon.

Roy, S., Tarafdar, M., Ragu-Nathan, T. S., \& Marsillac, E. (2012). The effect of misspecification of reflective and formative constructs in operations and manufacturing management. The Electronic Journal of Business Research Methods, $10(1), 34-52$.

Russell, M., Bebell, D., O’Dwyer, L., \& O’Connor, K. (2003). Examining teacher technology use implications for preservice and inservice teachers. Journal of Teacher Education, 54(4), 297-310.

Sang, G., Valcke, M., Van Braak, J., \& Tondeur, T. (2009). Investigating teachers' educational beliefs in Chinese primary schools: Socioeconomic and geographical perspectives. Asia-Pacific Journal of Teacher Education, 37(4), 363 - 377.

Santos, J. R. A. (1999). Cronbach's alpha: A tool for assessing the reliability of scales. Journal of Extension, 37(2), 1-5.

Solanas, A., Manolov, R., Leiva, D., \& Richards, M. M. (2011). Retaining principal components for discrete variables. Anario de Psicologia, 41(1-3), 33-50.

Stellefson, M., \& Hanic, B. (2008). Strategies for determining the number of factors to retain in exploratory factor analysis. Paper Presented at the Annual Meeting of the Southwest Educational Research Association, New Orleans.

Tanner, H., \& Jones, S. (2000). Using ICT to support interactive teaching and learning on a secondary mathematics PGCE course. Paper Presented at the British Educational Research Association Conference, Cardiff University.

Taylor, R. (1990). Interpretation of the correlation coefficient: A basic review. Journal of Diagnostic Medical Sonography, $1(6), 35-39$.

Teo, T. (2010). Examining the influence of subjective norm and facilitating conditions on the intention to use technology among pre-service teachers: A structural equation modeling of an extended technology acceptance model. Asia Pacific Education Review, 11, 253-262.

Teoo, T., Chai, C. S., Hung, D., \& Lee, C. B. (2008). Beliefs about teaching and uses of technology among pre-service teachers. Asia Pacific Journal of Teacher Education, 36(2), 163-174.

Teop, T. (2009a). Examining the relationship between student teachers' self-efficacy beliefs and their intended uses of technology for teaching: a structural equation modeling approach. The Turkish Online Journal of Educational Technology, 8(4), 7-16.

Teos, T. (2009b). Modeling technology acceptance in education: A study of pre-service teachers. Computers \& Education, 52(1), 302-312.

Tondeur, J., Van Braak, J., \& Valcke, M. (2007). Towards a typology of computer use in primary education. Journal of Computer Assisted Learning, 23, 197-206.

Usluel, Y. K., Askar, P., \& Bas, T. (2008). A structural equation model for ICT usage in higher education. Educational Technology \& Society, 11(2), 262-273.

Venkatesh, V., Morris, M. G., Davis, G. B., \& Davis, F. D. (2003). User acceptance of information technology: Toward a unified view. MIS Quarterly, 27(3), 425-478.

Voogt, J. (2010). Teacher factor associated with innovative curriculum goals and pedagogical practices: Differences between extensive and non-extensive ICT-using science teachers. Journal of Computer Assisted Learning, 26, 453643.

Voogts, J., Knezek, G., Cox, M., Knezek, D., \& Brummellhuis, A. T. (2011). Under which conditions does ICT have a positive effect on teaching and learning: A call to action. Journal of Computer Assisted Learning, 29(1), 4-14. 
Wanjala, M. S. M. (2010). Factors affecting the integration of computer in mathematics instruction in secondary schools in Bungoma district of Western Province, Kenya (Unpublished Doctoral Dissertation). Moi University, Eldoret.

Watkins, M. W. (2005). Determining parallel analysis criteria. Journal of Modern Applied Statistical Methods, 5(2), $344-346$.

Windschitl, M., \& Sahl, K. (2002). Tracing teachers' use of technology in a laptop computer school: The interplay of teacher beliefs, social dynamics, and institutional culture. American Educational Research Journal, 39(1), 165-205. 